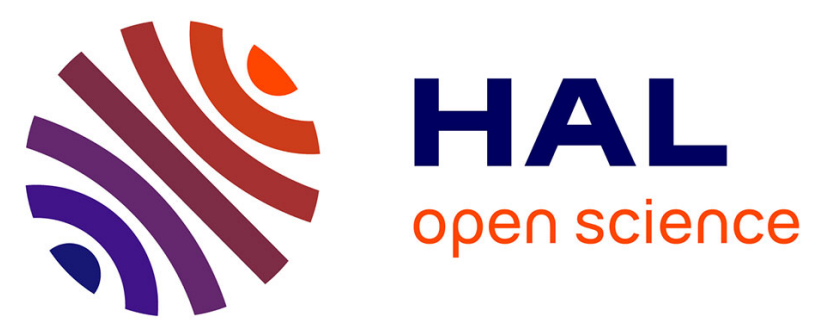

\title{
Electron deficient dicyanovinylene-ladder-type pentaphenylene derivative for n-type Organic Field Effect Transistors
}

Emmanuel Jacques, Maxime Romain, Ali Yassin, Sarah Bebiche, Maxime

Harnois, Tayeb Mohammed-Brahim, Joëlle Rault-Berthelot, Cyril Poriel

\section{To cite this version:}

Emmanuel Jacques, Maxime Romain, Ali Yassin, Sarah Bebiche, Maxime Harnois, et al.. Electron deficient dicyanovinylene-ladder-type pentaphenylene derivative for n-type Organic Field Effect Transistors. Journal of Materials Chemistry C, 2014, 2 (17), pp.3292-3302. 10.1039/C3TC31925C . hal-01066947

\section{HAL Id: hal-01066947 \\ https://hal-univ-rennes1.archives-ouvertes.fr/hal-01066947}

Submitted on 22 Sep 2014

HAL is a multi-disciplinary open access archive for the deposit and dissemination of scientific research documents, whether they are published or not. The documents may come from teaching and research institutions in France or abroad, or from public or private research centers.
L'archive ouverte pluridisciplinaire HAL, est destinée au dépôt et à la diffusion de documents scientifiques de niveau recherche, publiés ou non, émanant des établissements d'enseignement et de recherche français ou étrangers, des laboratoires publics ou privés. 


\title{
Electron deficient dicyanovinylene-ladder-type pentaphenylene derivative for n-type Organic Field Effect Transistors
}

\author{
Emmanuel Jacques, ${ }^{\mathrm{a}}$ Maxime Romain, ${ }^{\mathrm{b}}$ Ali Yassin, ${ }^{\mathrm{b}}$ Sarah Bebiche, ${ }^{\mathrm{a}}$ Maxime Harnois, ${ }^{\mathrm{a}}$ Tayeb \\ Mohammed-Brahim, ${ }^{\mathrm{a}}$ Joëlle Rault-Berthelot, ${ }^{\mathrm{b}}$ Cyril Poriel ${ }^{* \mathrm{~b}}$
}

a UMR CNRS 6164-Institut d'Électronique et des Télécommunications de RennesDépartement Microélectronique \& Microcapteurs, Bât.11B, Université Rennes 1, Campus de Beaulieu 35042 Rennes Cedex, France

${ }^{\mathrm{b}}$ UMR CNRS 6226-Institut des Sciences Chimiques de Rennes- Équipe Matière Condensée et Systèmes Électroactifs, Bat 10C, Campus de Beaulieu - 35042 Rennes cedex France

\begin{abstract}
A bridged pentaphenylene derivative functionalized with dicyanovinylene units $\mathbf{L P P}\left(=\mathbf{C}(\mathbf{C N})_{2}\right)_{2}$ has been designed, synthesized and characterized. The optical and electrochemical properties have been carefully studied through a combined experimental and theoretical approach and compared to those of two pentaphenylene derivatives bearing methylenes $(\mathbf{L P P})$ or carbonyl $\left(\mathbf{L P P}(=\mathbf{O})_{2}\right)$ on the bridgeheads. $\mathbf{L P P}\left(=\mathbf{C}(\mathbf{C N})_{2}\right)_{2}$ which possesses a very low LUMO level, ca $-4.02 \mathrm{eV}$, has been successfully used as active layer in n-channel OFETs using epoxy based photoresist SU-8 as gate insulator. $\mathbf{L P P}\left(=\mathbf{C}(\mathbf{C N})_{2}\right)_{2}$ based n-channel OFETs show low voltage functioning (low gate-source and drain-source voltages), high ratio between the on and the off currents $\left(2 \times 10^{5}\right)$, interesting subthreshold swing $(S=1)$ and excellent stability under electrical stress and under nitrogen atmosphere. More importantly, we have also shown that $\mathbf{L P P}\left(=\mathbf{C}(\mathbf{C N})_{2}\right)_{2}$ based n-channel OFETs present an excellent environmental stability. This work is to the best of our knowledge the first report of bridged pentaphenylene-based semiconductor in n-type OFET and highlights the potential of such type of materials to provide air stable OFET.
\end{abstract}

\section{Introduction}

Organic Field Effect Transistors (OFETs) have attracted impressive interest in the recent years due to possible incorporation in full organic electronic devices. ${ }^{1}$ Of particular interest for the future of this technology are the electron transporting n-type OFETs. ${ }^{2,3}$ Despite the recent breakthroughs in the field, which have led to electron transporting materials (n-type) with mobility of negative charges up to unity, the number of n-type molecules is still very limited compared to hole transporting (p-type) molecules. ${ }^{1-3}$ Thus, designing efficient $n$-type materials for air-stable OFET is still an important challenge for the future of Organic Electronic since the instability of organic radical anions (generated by reduction of the active layer at the cathode) in the presence of oxygen and water avoids the OFET to work under ambient conditions. ${ }^{2}$ Indeed, the potential at which an n-type doped molecule can be oxidized should be higher than $-0.658 \mathrm{~V}$ (vs SCE) in order to be stable towards water reduction $\left(2 \mathrm{H}_{2} \mathrm{O}\right.$ 
$\left.+2 \mathrm{e}^{-} \rightarrow \mathrm{H}_{2}+2 \mathrm{OH}^{-}\right) .^{4,5^{*}}$ It is hence usually accepted that molecules with a lowest unoccupied molecular orbital (LUMO) lower than $-4 \mathrm{eV}$ may lead to air stable n-type OFET. ${ }^{2}$ In addition, the reduced injection barrier between commonly used stable metals (Au, $\mathrm{Al}, \mathrm{Mo} . .$.$) and low$ LUMO-level materials leads to low threshold voltages. Thus, these two key parameters to obtain air stable and low threshold voltage n-type OFETs, are linked to the energy of the LUMO level and its compatibility with usual metals. The design strategy to obtain n-type materials usually consists to judiciously introduce electron withdrawing groups or atoms (carbonyls, dicyanovinylenes, imides, halogens etc) to a $\pi$-conjugated core. However, the restricted diversity of $\pi$-conjugated systems developed (mainly based on thiophene or fused thiophene, perylene and naphthalene) $)^{3}$ has led us to focus on other molecular fragments barely investigated in the literature, ie. linear bridged extended oligophenylenes. Indeed, bridged extended oligophenylenes such as tri- (dihydroindeno[1,2-b]fluorene), ${ }^{6-14}$ and pentaphenylenes ${ }^{15-19}$ are promising compounds for blue emitting Organic Light Emitting Device (OLED) applications but have been rarely used as active layer in n-type OFETs. ${ }^{5,20-22}$ The pioneering works of Marks and Facchetti have nevertheless shown in 2008 the high potential of dihydroindeno[1,2-b]fluorene and bridged tetraphenylenes combined to dicyanovinylene units to obtain promising air stable n-type OFETs., ${ }^{2,20,23}$ These pioneering works have paved the way to the design of n-type materials based on bridged phenylene scaffold incorporating for example intracyclic nitrogen atoms (ie pyrazine) ${ }^{24}$ or pendant halogen atoms. ${ }^{25}$ With this in mind, we wish to report in this work the synthesis, characterization and application in ntype OFETs of a new Ladder-type PentaPhenylene (LPP) derivative bearing on the two central bridgeheads highly deficient dicyanovinylene functionalities. The optical and electrochemical properties have been studied in detail through a combined experimental and theoretical approach and compared to those of two pentaphenylene derivatives bearing methylenes or carbonyl units on the bridgeheads. $\mathbf{L P P}\left(=\mathbf{C}(\mathbf{C N})_{2}\right)_{2}$ has been finally used as active layer in n-channel OFETs using epoxy based photoresist SU-8 as gate insulator leading to very promising devices presenting excellent environmental stability. This work not only represents the first report of pentaphenylene-based semiconductor in n-type OFET but highlights the great potential of such type of materials to provide air stable OFET.

\section{$\underline{\text { Results and discussion: }}$}

\section{Design and Synthesis.}

The molecular design adopted in this work is the following: (i) the $\pi$-conjugated pentaphenylenyl core has been rigidified by four bridges in order to increase the flatness of the $\pi$-conjugated molecular system. This rigidification should maximize the $\pi$-electron delocalization and allow an efficient intermolecular $\pi-\pi$ stacking in the solid state, essential for electron hopping (ii) the electron-withdrawing dicyanovinylene groups have been introduced on the bridgeheads of the pentaphenylene core to lower the LUMO energy level without disrupting the $\pi$-conjugation, crucial points for achieving efficient electron injection/transport (iii) alkyl side chains $\left(\mathrm{R}=n-\mathrm{C}_{8} \mathrm{H}_{17}\right)$ have been connected to the side bridgeheads to increase the solubility of the molecule. It is indeed known that bridged oligophenylenes are often non soluble in common organic solvents, rendering them difficult to process.

\footnotetext{
* It should be stressed that obtaining n-type materials stable towards both water and oxygen reduction is an even more challenging task as they should be reduced at a very high potential, that is higher than $+0.571 \mathrm{~V}$ (vs $\mathrm{SCE})^{4,5}$
} 


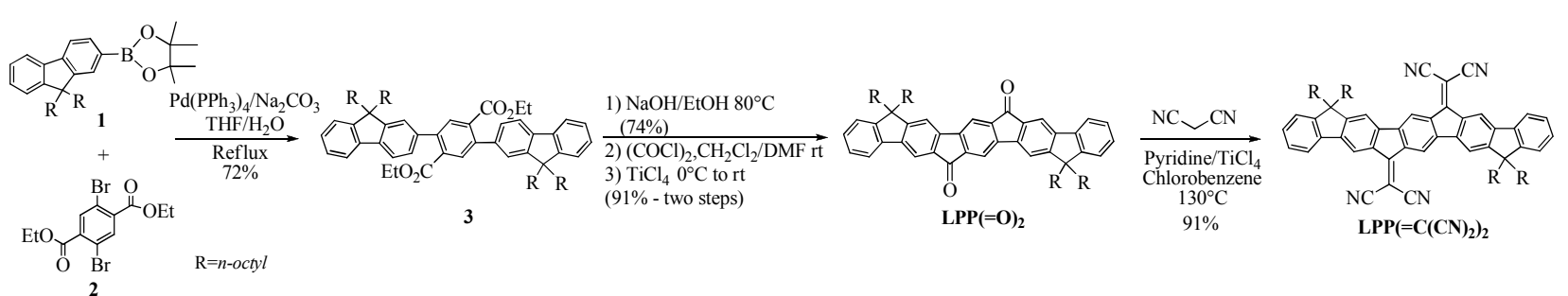

Scheme 1. Synthesis of $\mathbf{L P P}\left(=\mathbf{C}(\mathbf{C N})_{2}\right)_{2}$

The synthesis of $\mathbf{L P P}\left(=\mathbf{C}(\mathbf{C N})_{2}\right)_{2}$ involves the synthesis of the key fragment $\mathbf{L P P}(=\mathbf{O})_{\mathbf{2}}$ previously reported. ${ }^{15} \mathbf{L P P}(=\mathbf{O})_{2}$ will be also used in the following of this work as a model compound in order to precisely study the properties of $\mathbf{L P P}\left(=\mathbf{C}(\mathbf{C N})_{2}\right)_{2}$ and especially the effect of the incorporation of electron withdrawing units $\left(=\mathrm{C}(\mathrm{CN})_{2}\right.$ vs $\left.\mathrm{CO}\right)$ on the pentaphenylene core. The first step of this synthetic approach starts with the Suzuki-Myaura cross-coupling of the 2-fluorene boronate $\mathbf{1}$ and the dibromoterephthalate $\mathbf{2}$ to provide with high yields the difluorenyl phenyldiester $3 .{ }^{15}$ Saponification of $\mathbf{3}$, in basic conditions, provides the corresponding terephthalic acid, further converted into its acid dichloride, which finally leads to the diketone $\mathbf{L P P}(=\mathbf{O})_{2}$ through a Lewis acid-promoted intramolecular Friedel-Craft acylation $\left(\mathrm{TiCl}_{4}, 0^{\circ} \mathrm{C}\right){ }^{26}$ Finally, Knoevenagel condensation of $\mathbf{L P P}(=\mathbf{O})_{2}$ in the presence of pyridine and $\mathrm{TiCl}_{4}$ (used as Lewis acid to activate the carbonyl groups) provides the dimalononitrile pentaphenylene $\mathbf{L P P}\left(=\mathbf{C}(\mathbf{C N})_{2}\right)_{2}$ with $91 \%$ yield. $\mathbf{L P P}\left(=\mathbf{C}(\mathbf{C N})_{2}\right)_{2}$ is highly soluble in common organic solvents due to the presence of four octyl chains on the two side bridgeheads.

Dicyanovinylene is a strong electron-withdrawing unit and its electronic effect on the pentaphenylene core can be interestingly visualized by ${ }^{1} \mathrm{H}$ NMR spectroscopy. Indeed, ${ }^{1} \mathrm{H}$ NMR spectroscopy is a powerful tool to evaluate the strength of electron withdrawing/donating moieties on the environnement. ${ }^{27}$ Thus, the strength of the electron withdrawing character of the dicyanovinylene group compared for example to its carbonyl analogue can be directly correlated to the resulting shielding/deshielding effects of the hydrogen atoms of the pentaphenylene backbone. Thus, in the ${ }^{1} \mathrm{H}$ NMR spectrum of $\mathbf{L P P}(=\mathbf{O})_{2}$, the hydrogen atoms $\mathrm{H}_{1} / \mathrm{H}_{2}$ in $\beta$ position of the carbonyl unit are the most deshielded hydrogens with resonances found at 8 and $7.86 \mathrm{ppm}$ respectively (Figure 1, Top). ${ }^{*}$

Switching from a carbonyl to a dicyanovinylene unit leads to an impressive deshielding effect for both $\mathrm{H}_{1} / \mathrm{H}_{2}$ respectively recorded at $8.73 \mathrm{ppm}$ and $8.57 \mathrm{ppm}$ in $\mathbf{L P P}\left(=\mathbf{C}(\mathbf{C N})_{2}\right)_{2}$ (Figure 1, Bottom). This clearly translates the stronger electron withdrawing character of the dicyanovinylene fragment compared to that of the carbonyl group, which in turn should lead to different electronic properties (see below). Modifying the nature of the bridge is hence an interesting strategy to tune the electronic properties of a pentaphenylene core. It should be nevertheless mentioned that the chemical shift of $\mathrm{H}_{3}$ is identical for both $\mathbf{L P P}(=\mathbf{O})_{2}$ and $\mathbf{L P P}\left(=\mathbf{C}(\mathbf{C N})_{2}\right)_{2}, \delta_{\mathrm{H} 3}=7.52 \mathrm{ppm}$, indicating that the effect of the bridge is completely vanished on this position.

\footnotetext{
${ }^{*}$ The assignments have been performed by 2D NMR spectroscopy.
} 

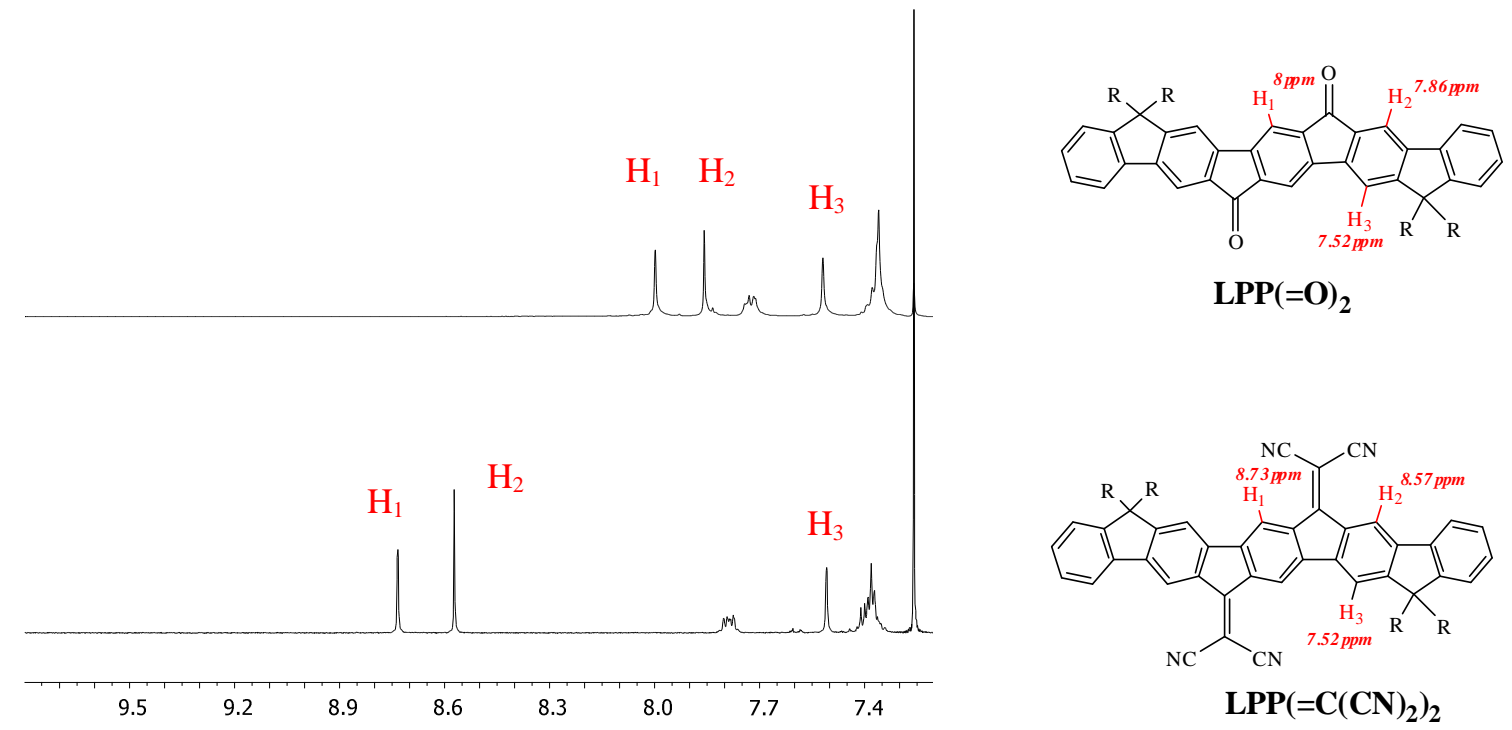

Figure 1. Low-field portion of the ${ }^{1} \mathrm{H}$ NMR spectra $\left(\mathrm{CDCl}_{3}, \mathrm{rt}\right)$ of $\mathbf{L P P}(=\mathbf{O})_{2}$ (top), and $\mathbf{L P P}\left(=\mathbf{C}(\mathbf{C N})_{2}\right)_{2}$ (bottom).

\section{Electrochemical properties}
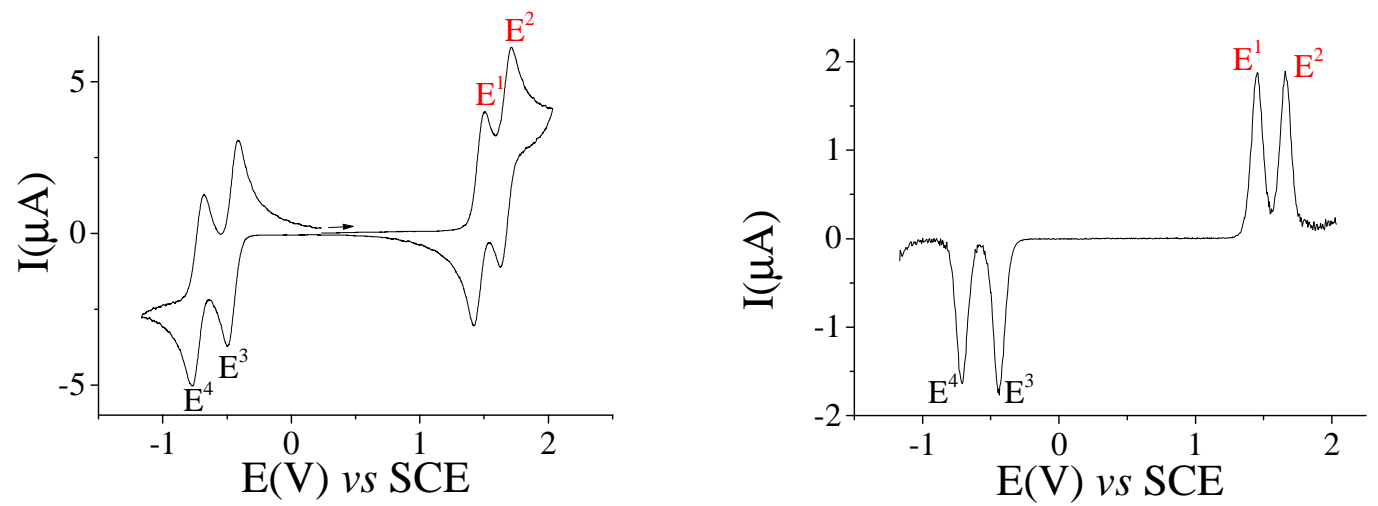

Figure 2. Cyclic voltammetry of $\mathbf{L P P}\left(=\mathbf{C}(\mathbf{C N})_{2}\right)_{2}$ 2. $10^{-3} \mathrm{M}$ in $\mathrm{CH}_{2} \mathrm{Cl}_{2}\left(\mathrm{Bu}_{4} \mathrm{NPF}_{6} 0.2 \mathrm{M}\right)$, working electrode:Platinum disk diameter $1 \mathrm{~mm}$, sweep rate: $100 \mathrm{mV} / \mathrm{s}$. Right : Differential Pulse Voltammetry in oxidation and reduction of the same solution (Pulse Height: $25.10^{-3} \mathrm{~V}$; Scan-rate: 5 mV.s ${ }^{-1}$; Pulse Width: $100 \mathrm{~ms}$ ).

$\mathbf{L P P}\left(=\mathbf{C}(\mathbf{C N})_{2}\right)_{2}$ presents in dichloromethane four isoelectronic and reversible oxidation and reduction waves (Figure 2). This behaviour is similar to that previously observed for $\mathbf{L P P}(=\mathbf{O})_{2}{ }^{15}$ both molecules being oxidized at nearly the same potential $\left(\mathrm{E}^{1} / \mathrm{E}^{2}: 1.4 / 1.68 \mathrm{~V}\right.$ for $\mathbf{L P P}(=\mathbf{O})_{2}$ and $1.50 / 1.71 \mathrm{~V}$ for $\mathbf{L P P}\left(=\mathbf{C}(\mathbf{C N})_{2}\right)_{2}$, vs SCE). Thus, in the anodic range, the difference between the two electron-withdrawing groups (carbonyl and dicyanovinylene units) appears to be weak. However, these potential values are strongly more anodic than those of the non functionalized analogue Ladder PentaPhenylene LPP with methylene bridges $(0.99 / 1.36 \mathrm{~V})$, previously reported in the literature. ${ }^{16}$ This impressive shift (by ca $400 \mathrm{mV}$ for $\mathbf{L P P}(=\mathbf{O})_{2} /$ and by ca $500 \mathrm{mV}$ for $\mathbf{L P P}\left(=\mathbf{C}(\mathbf{C N})_{2}\right)_{2}$, ) is clearly indicative of the strong electron-withdrawing character of the ketone and dicyanovinylene units on the oxidation of the pentaphenylene backbone. The onset oxidation potentials measured at $1.27 \mathrm{~V}$ for 
$\mathbf{L P P}(=\mathbf{O})_{2}$ and $1.39 \mathrm{~V}$ for $\mathbf{L P P}\left(=\mathbf{C}(\mathbf{C N})_{2}\right)_{2}$, lead to HOMO levels respectively lying at -5.67 $\mathrm{eV}$ and at $-5.79 \mathrm{eV}$ (Table 1), both being deeper than that of LPP $(-5.27 \mathrm{eV})$.

In the cathodic range, $\mathbf{L P P}(=\mathbf{O})_{2}$ reduction $\left(\mathrm{E}^{3} / \mathrm{E}^{4}\right)$ occurs at -1.07 and $-1.52 \mathrm{~V}$ and these two electron transfers have been assigned to the reduction of the diketone to the quinonoidal dianion. ${ }^{15}$ The reduction of $\mathbf{L P P}\left(=\mathbf{C}(\mathbf{C N})_{2}\right)_{2}$ occurs at -0.495 and $-0.77 \mathrm{~V}$ impressively positively shifted compared to $\mathbf{L P P}(=\mathbf{O})_{2}$ (figure 2 ). In this case, and oppositely to the above conclusions in oxidation, this clearly indicates the stronger electron withdrawing character of the dicyanovinylene fragment compared to that of the carbonyl group. In addition, the reduction of both molecules is remarkably easier than that of LPP which presents a single bielectronic irreversible reduction wave at $-2.39 \mathrm{~V} .{ }^{16}$ Thus, compared to LPP, the substitution with cyanovinylene units in $\mathbf{L P P}\left(=\mathbf{C}(\mathbf{C N})_{2}\right)_{2}$ renders the reduction easier by ca $2 \mathrm{~V}$, translating the strong withdrawing effect induced by the substituents on the pentaphenylene unit and highlighting hence the efficiency of the present chemical design. The onset reduction potentials pointed out at $-0.92 \mathrm{~V}$ for $\mathbf{L P P}(=\mathbf{O})_{2}$ and at $-0.38 \mathrm{~V}$ for $\mathbf{L P P}\left(=\mathbf{C}(\mathbf{C N})_{2}\right)_{2}$, respectively leading to LUMO levels lying at -3.48 and $-4.02 \mathrm{eV}$, remarkably lower than that of LPP $(-2.19 \mathrm{eV})$, Table 1. Thus, compared to LPP, the LUMO energy of $\mathbf{L P P}(=\mathbf{O})_{2}$ and $\mathbf{L P P}\left(=\mathbf{C}(\mathbf{C N})_{2}\right)_{2}$ is strongly affected by the substitution of the bridges which is clearly not the case for their HOMO energy, which is only slightly affected. This suggests that the LUMOs are localized on the bridges, hence rendering these LUMO levels more sensitive to bridges functionalization. Oppositely, the HOMOs are more delocalized over the pentaphenylene core and are hence less sensitive to bridges functionalization. This has been confirmed through theoretical calculations pointing out, for both $\mathbf{L P P}(=\mathbf{O})_{2}$ and $\operatorname{LPP}\left(=\mathbf{C}(\mathbf{C N})_{2}\right)_{2}$ (i) a LUMO level with electron densities localized on the bridge and on the centre of the aromatic core and (ii) a HOMO level with a pentaphenylene character (see nature of the orbitals in Figure 3 middle and right). We note that the non-substituted LPP has both LUMO and HOMO levels localized on the pentaphenylene core with no density on the methylene bridges (Figure 3-left). To the best of our knowledge, the LUMO energy of $\mathbf{L P P}\left(=\mathbf{C}(\mathbf{C N})_{2}\right)_{2}(-4.02 \mathrm{eV})$ is among the lowest reported for a bridged oligophenylene derivative and even the lowest reported for a pentaphenylene core. 2,328 This feature (LUMO lower than $-4 \mathrm{eV}$ ) is a key point for charge injection and to obtain environmentally stable OFETs (see below)., 2

LUMO
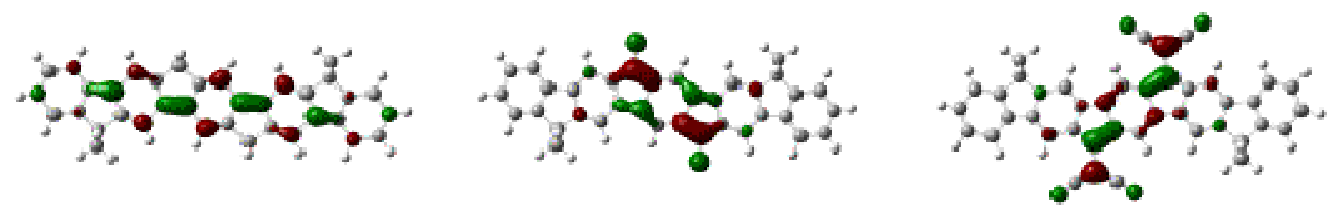

HOMO

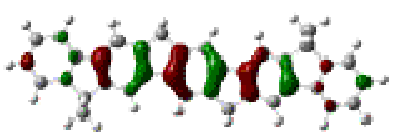

LPP

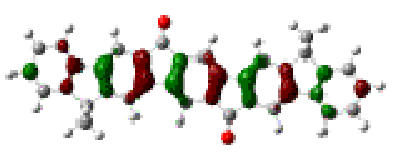

$\operatorname{LPP}(=\mathrm{O})_{2}$

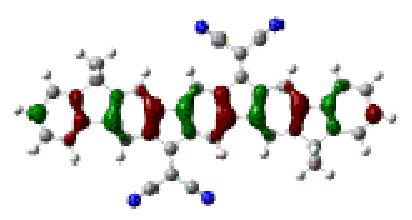

$\operatorname{LPP}\left(=\mathrm{C}(\mathrm{CN})_{2}\right)_{2}$

Figure 3. Sketch of frontier molecular orbitals of a simplified model of $\mathbf{L P P}$ (left) $\mathbf{L P P}(=\mathbf{O})_{2}$ (middle) and $\mathbf{L P P}\left(=\mathbf{C}(\mathbf{C N})_{2}\right)_{2}$ (right) (methyl instead of octyl groups) from DFT calculations (see details in experimental part) 
The electrochemical gap $\Delta \mathrm{E}^{\mathrm{el}}$, defined as the HOMO-LUMO difference obtained from electrochemical data, were calculated as $2.19 \mathrm{eV}$ for $\mathbf{L P P}(=\mathbf{O})_{2}$ and $1.77 \mathrm{eV}$ for $\mathbf{L P P}\left(=\mathbf{C}(\mathbf{C N})_{2}\right)_{2}$ that is largely lower than that of $\mathbf{L P P}\left(\Delta \mathrm{E}^{\mathrm{el}}=3.08 \mathrm{eV}\right)$, Table $1 . \Delta \mathrm{E}^{\mathrm{el}}$ are in accordance with the trend observed in the optical gaps $\left(\Delta \mathrm{E}^{\mathrm{opt}}=3.12 \mathrm{ev}\right.$ for $\mathbf{L P P}, \Delta \mathrm{E}^{\mathrm{opt}}=2.07$ ev for $\mathbf{L P P}(=\mathbf{O})_{2}$ and $\Delta \mathrm{E}^{\mathrm{opt}}=1.53 \mathrm{eV}$ for $\mathbf{L P P}\left(=\mathbf{C}(\mathbf{C N})_{2}\right)_{2}$, Table 1) with the same contraction of $0.4 / 0.5 \mathrm{eV}$ when switching from carbonyl to dicyanovinylene bridges. Compared to theoretical values obtained through DFT calculations (Table 1), the HOMO/LUMO energy levels appear to be in accordance despite a slight deviation. These deviations lead to theoretical gaps, $\Delta \mathrm{E}^{\text {th }}$, with a difference of ca $0.5 / 0.6 \mathrm{eV}$ compare to experimental data with however a similar trend.

\section{$U V$-Vis absorption spectra}

UV-Vis absorption spectra are shown in figure 4 and optical data are collected in Table 1.

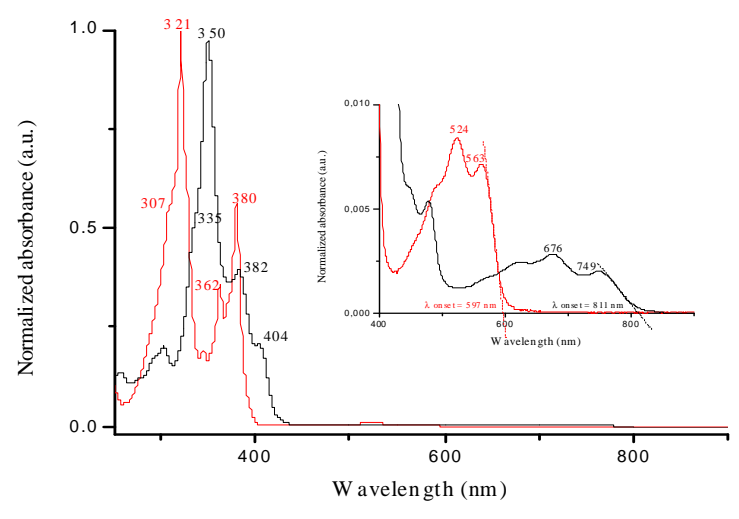

Figure 4. Normalized UV-Vis spectra of $\mathbf{L P P}(=\mathbf{O})_{2}$ (red), $\mathbf{L P P}\left(=\mathbf{C}(\mathbf{C N})_{2}\right)_{2}$ (black), in solution in cyclohexane Inset: focus on the $400 / 900 \mathrm{~nm}$ portion of the spectra $\left(\mathrm{n}-\pi^{*}\right.$ transitions).

Table 1. Electrochemical and optical properties of $\mathbf{L P P}, \operatorname{LPP}(=\mathbf{O})_{2}$ and $\operatorname{LPP}\left(=\mathrm{C}(\mathrm{CN})_{2}\right)_{2}$.

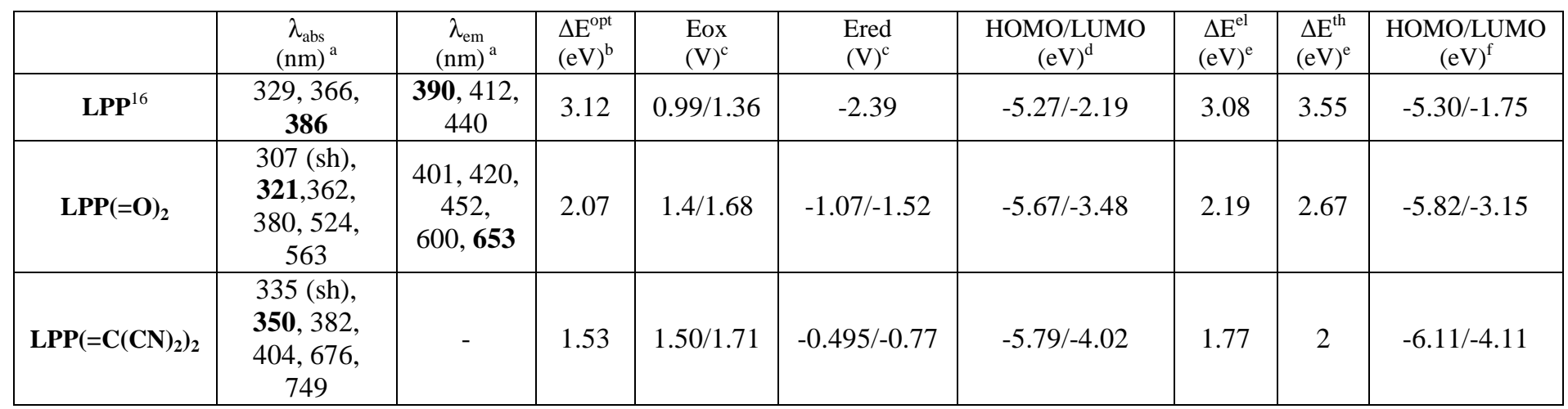

a: in cyclohexane (in bold the more intense band), b: $\Delta \mathrm{E}^{\mathrm{opt}}[\mathrm{eV}]=\mathrm{hc} / \lambda, \lambda$ being the low energy absorption band edge (in meter, see Figure 4-inset), with $\mathrm{h}=6.6 \times 10^{-34} \mathrm{~J} . \mathrm{s}\left(1 \mathrm{eV}=1.6 \times 10^{-19} \mathrm{~J}\right)$ and $\mathrm{c}=3.0 \times 10^{8} \mathrm{~m} \cdot \mathrm{s}^{-1}$, this equation may be simplified as: $\Delta \mathrm{E}^{\mathrm{opt}}(\mathrm{eV})=1237.5 / \lambda$ (in $\mathrm{nm}$ ), c: $v s$ SCE, $\mathrm{d}$ : calculated from onset oxidation/reduction potential taken from $\mathrm{CV}$ (Figure 2 ), ${ }^{29,30} \mathrm{e}$ : from electrochemical data $\Delta \mathrm{E}^{\mathrm{el}}=$ HOMO-LUMO, f: from theoretical calculations. 
In solution in cyclohexane, $\mathbf{L P P}(=\mathbf{O})_{2}$ presents the typical absorption bands $(\lambda=321,362$ and $380 \mathrm{~nm}$ ) of a pentaphenylene ladder type analogue such as the non functionalized analogue LPP $(\lambda=329 / 366 / 386 \mathrm{~nm})$ which have been assigned to $\pi-\pi *$ transitions. ${ }^{16}$ Due to the presence of two chromophores i.e. pentaphenylene and aryl ketone, very weak absorption bands were also observed at lower energy ca 524/563 $\mathrm{nm}$. At this stage, these bands have intuitively assigned to symmetry forbidden $n-\pi *$ transitions of the carbonyl function. ${ }^{15,31,32}$ The absolute absorption maximum of $\mathbf{L P P}(=\mathbf{O})_{2}$ is shifted to longer wavelengths by around $100 \mathrm{~nm}$ compared to that of indeno[1,2-b]fluorene-6,12-dione $\left(\lambda_{\max }=289 \mathrm{~nm}\right.$ in $\left.\mathrm{CH}_{2} \mathrm{Cl}_{2}\right){ }^{15}$ This bathochromic shift is indicative of enhanced $\pi$-conjugation of the molecular backbone and is assigned to the planar ladder-type structure of the pentaphenylene core bearing two electron-withdrawing carbonyl groups. By replacing the carbonyl groups with the dicyanovinylene groups, all the maxima are shifted by around $20 / 25 \mathrm{~nm}$ in $\mathbf{L P P}\left(=\mathbf{C}(\mathbf{C N})_{2}\right)_{2}$ due to extended conjugation induced by the dicyanovinylene units. The bathochromic shift upon dicyanovinylene functionalization is fully consistent with the reported shifts observed for similar ladder structures ${ }^{20,23,33}$ and mainly attributed to the decrease of the LUMO level due to the stronger electron-withdrawing nature of the dicyanovinylene compared to the carbonyl group, resulting in an optical gap contraction from $\Delta \mathrm{E}^{\mathrm{opt}}=2.07 \mathrm{eV}\left(\mathbf{L P P}(=\mathbf{O})_{2}\right)$ to $\Delta \mathrm{E}^{\mathrm{opt}}=1.53 \mathrm{eV}\left(\mathbf{L P P}\left(=\mathbf{C}(\mathbf{C N})_{2}\right)_{2}\right)$, table 1 . These energy gaps $\Delta \mathrm{E}^{\mathrm{opt}}$ determined from the low-energy band edge (see below the assignment of this band in Time Dependent DFT analyses, TD-DFT) are strongly contracted compared to that of its non functionalized analogue LPP $(3.12 \mathrm{eV})^{16}$ due to HOMO/LUMO decrease with a more important magnitude in the latter (see above). TD-DFT calculations have been performed and have allowed to assign the low energy band in both $\mathbf{L P P}(=\mathbf{O})_{2}$ and $\mathbf{L P P}\left(=\mathbf{C}(\mathbf{C N})_{2}\right)_{2}$ to an HOMO/LUMO transition (See SI). Thus, experimental optical gaps $\Delta \mathrm{E}^{\mathrm{opt}}$, presented above (Table 1), should provide an accurate estimation of the HOMO/LUMO difference and are in accordance with those obtained from electrochemical data (see above). The difference observed between $\Delta \mathrm{E}^{\mathrm{Opt}}$ and $\Delta \mathrm{E}^{\mathrm{El}}(0.12 / 0.14 \mathrm{eV})$ can be assigned to the different processes involved (optical transition vs redox reaction). In addition, it should be stressed that the band recorded at $380 \mathrm{~nm}$ for $\mathbf{L P P}(=\mathbf{O})_{2}$ has been assigned to an HOMO/LUMO+1 transition whereas the main strong band at ca $320 \mathrm{~nm}$ may involved several other 'transitions' mainly HOMO-6/LUMO and HOMO7/LUMO (See TDDFT analyses in SI). Compared to $\mathbf{L P P}(=\mathbf{O})_{2}, \mathbf{L P P}\left(=\mathbf{C}(\mathbf{C N})_{2}\right)_{2}$ also presents a larger red shift of the low energy band (563 vs $749 \mathrm{~nm}$, Table 1) than that of the $\pi-\pi *$ transitions. This feature confirms that these low energy transitions (assigned to $\mathrm{n}-\pi^{*}$ transitions) have a significant contribution of frontier molecular orbitals localized on the bridges and are hence more sensitive to the substitution (see nature of the molecular orbital involved in the low energy band in TDDFT analyses in SI and in Figure 3). Solvatochromic experiments have been then carried out to gain further insight in the photophysical properties. Although the short-wavelength absorption maxima of $\mathbf{L P P}(=\mathbf{O})_{2}$ only show very small solvatochromism (several nanometres), the long-wavelength absorptions display large redshifts $(524 \mathrm{~nm}$ in cyclohexane to $552 \mathrm{~nm}$ in ethanol), indicating positive solvachromatism (Figure 5). Since blue-shifts are usually expected for $n-\pi^{*}$ absorptions when increasing the solvent polarity, ${ }^{5}, 34$ the red-shift observed in this case seems to indicate that the FranckCondon excited state (first excited state $S_{1}\left(n-\pi^{*}\right)$ ) has a more polar character than the ground state. Similar observations have been recently done by Marks and coworkers for structurally related compounds. ${ }^{5}$ 

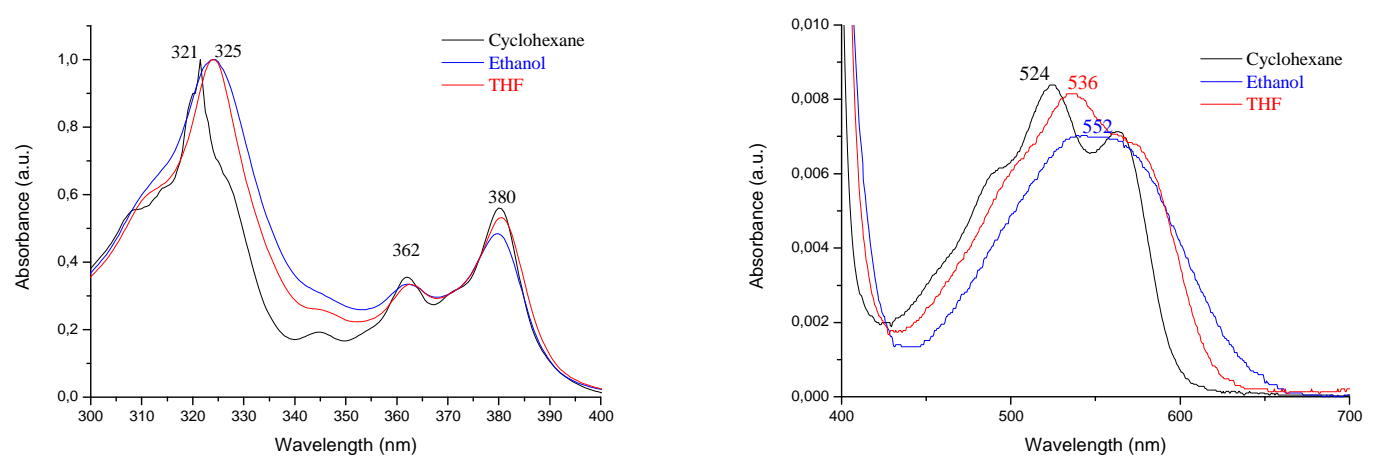

Figure 5. Absorption spectra of $\mathbf{L P P}(=\mathbf{O})_{2}$ (Left: $300 / 400 \mathrm{~nm}$ range, right: $400 / 700 \mathrm{~nm}$ range) in cyclohexane (black line), in THF (red line) and in ethanol (blue line).

$\mathbf{L P P}\left(=\mathbf{C}(\mathbf{C N})_{2}\right)_{2}$ displays a different behaviour. Indeed, a blue shift of the long wavelength transition is observed, characteristic of $n-\pi^{*}$ transitions (Figure 6). Indeed, Zerner and coworkers have proposed that the interactions with the solvent lower the ground state energy of the molecule more than they lower the excited state energy, leading hence to a blue shift of the band. ${ }^{34}$ This seems to be the case of $\mathbf{L P P}\left(=\mathbf{C}(\mathbf{C N})_{2}\right)_{2}$. It should be nevertheless mentioned that bathochromic vs hypsochromic shift of such $n-\pi^{*}$ transitions has been the subject of numerous studies and controversies. ${ }^{34}$
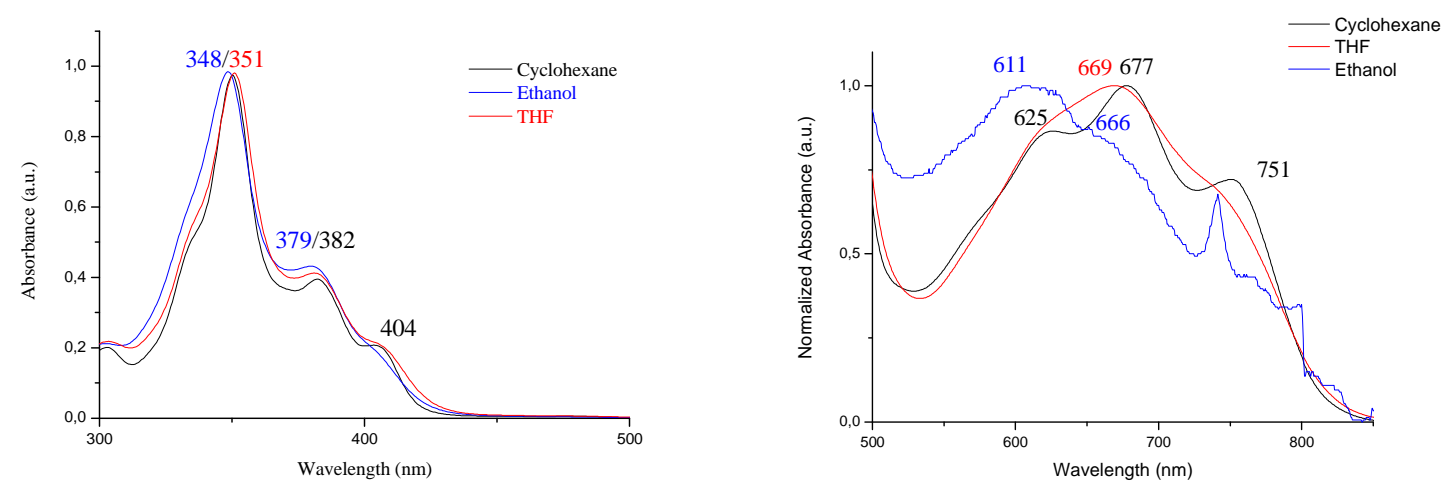

Figure 6. Absorption spectra of $\mathbf{L P P}\left(=\mathbf{C}(\mathbf{C N})_{2}\right)_{2}$ (Left: $300 / 500 \mathrm{~nm}$ range, right: $800 / 850 \mathrm{~nm}$ range,) in cyclohexane (black line), in THF (red line) and in ethanol (blue line)

\section{Fluorescence spectroscopy}

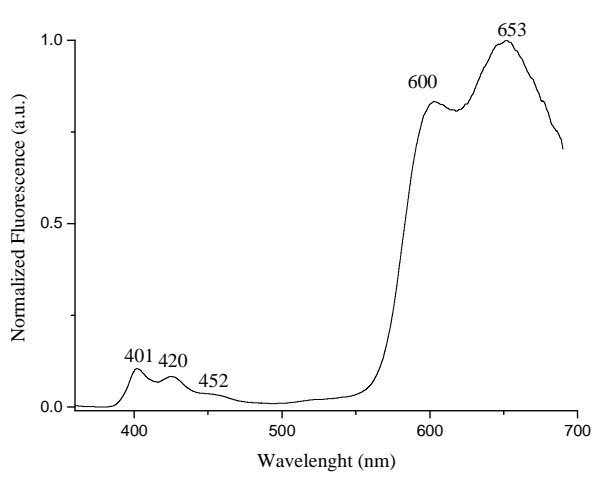

Figure 7. Fluorescence spectrum of $\mathbf{L P P}(=\mathbf{O})_{2}$ in cyclohexane $(\lambda \mathrm{ex}=350 \mathrm{~nm})$ 
The fluorescence spectrum of $\mathbf{L P P}(=\mathbf{O})_{2}$ displays two sets of emission bands $(\lambda=401 / 420 \mathrm{~nm}$ and $600 / 653 \mathrm{~nm}$, Figure 7). The weak contributions in the blue region $(401 / 420 \mathrm{~nm})$ are in perfect accordance in shape and wavelength with the fluorescence of the analogue pentaphenylene LPP (390/412/440 nm). ${ }^{16}$ However, the main fluorescence is clearly observed at lower energy with a large band with maxima at $600 / 653 \mathrm{~nm}$. The assignment of such low energy band and its relation with the presence of keto functions has been the purpose of numbers of studies (in the field of blue OLEDs) in order to determine its origin and the deactivation mechanisms involved. ${ }^{17,35,26,27}$ As recently proposed for other oligophenylene derivatives bearing keto units, ${ }^{36,37}$ the large band of $\mathbf{L P P}(=\mathbf{O})_{2}$ at $600 / 653 \mathrm{~nm}$ is assigned to intermolecular interactions between the ketone units. Thus, the dual fluorescence observed for $\mathbf{L P P}(=\mathbf{O})_{2}$ is due to the emission (i) of the pentaphenylene core and (ii) dimer of pentaphenylenedione due to dipole-dipole interactions between the ketones bridges. ${ }^{36,37}$ When increasing solvent polarity from cyclohexane to THF, fluorescence spectra of $\mathbf{L P P}(=\mathbf{O})_{2}$ exhibits positive solvachromatisms of the low energy band (cyclohexane: 603/651 nm, THF:632/684 nm, see Figure S3 in SI) but not of the high energy band. The red shift of the low energy band is even larger than that observed in the absorption spectra, indicating that the dipole moment is larger in the excited state than in the ground state. This dependence of the emission wavelength on the solvent polarity is indicative of dipole-dipole interactions between $\mathbf{L P P}(=\mathbf{O})_{2}$ and polar solvent molecules and hence of a photoinduced intramolecular charge transfer. In the different solvent tested, $\mathbf{L P P}\left(=\mathbf{C}(\mathbf{C N})_{2}\right)_{2}$ displays almost no significant fluorescence (or too weak to be properly mentionned). This emission quenching has been previously assigned for related structures to non-radiative internal energy/electron transfers between pentaphenylene core and dicyanovinylene units before emission. ${ }^{20}$

\section{Organic Field Effect Transistors}

The potential of pentaphenylene-based semiconductor $\mathbf{L P P}(=\mathbf{O})_{2}$ and $\mathbf{L P P}\left(=\mathbf{C}(\mathbf{C N})_{2}\right)_{2}$ as active layer of $n$-channel organic thin film transistors (n-OFETs) has been evaluated through the fabrication and the electrical characterization of n-type OFETs. Usual Bottom Gate Bottom Contacts architecture of OFETs was chosen (Figure 8c). The choice of epoxy based photoresist SU-8 as gate insulator in the present devices is mainly due to our need to reach in the near future fully organic OFET and in order to better understand the organic-organic interface, key feature in OFET and in organic electronics in general.

The electrical properties of such OFETs were extracted under nitrogen atmosphere from transfer and output characteristics presented Figures 8a-b. The most important parameters are (i) the mobility $\mu_{\mathrm{FE}}$ linked to the frequency operation in CMOS devices, (ii) the threshold voltage $\mathrm{V}_{\mathrm{TH}}$ that determines the working voltage of OFET and (iii) on/off values of the drain - source resistance $\mathrm{R}_{\mathrm{DS}}$ linked to the on and off status of an FET in CMOS circuits.

First, regarding $\mathbf{L P P}(=\mathbf{O})_{2}$, no field effect activity was detected. This conclusion is in accordance with that obtained for dihydroindeno[1,2- $b]$ fluorene (3 phenyl rings) and tetraphenylenes (4 phenyl rings) bridged with carbonyl units, ${ }^{5}$ indicating that the carbonyl units do not allow decreasing enough the LUMO energy to favour the charge injection. $\mathbf{L P P}\left(=\mathbf{C}(\mathbf{C N})_{2}\right)_{2}$ displays a drastically different behaviour clearly assigned to the strong decrease of the LUMO level highlighted above $\left(-3.48 \mathrm{eV}\right.$ for $\mathbf{L P P}(=\mathbf{O})_{2}$ vs $-4.02 \mathrm{eV}$ $\left.\mathbf{L P P}\left(=\mathbf{C}(\mathbf{C N})_{2}\right)_{2}\right)$. Quantitatively, the parameters of the present OFETs have been calculated following known equations provided in experimental part (see below).

For $\mathbf{L P P}\left(=\mathbf{C}(\mathbf{C N})_{2}\right)_{2}$, transfer characteristics, drain-source current $\mathrm{I}_{\mathrm{DS}}$ as a function of the gate-source voltage $\mathrm{V}_{\mathrm{GS}}$, was plotted at constant drain-source voltage $\mathrm{V}_{\mathrm{DS}}$. The value of $\mathrm{V}_{\mathrm{DS}}$ 
was chosen sufficiently low to be in the linear regime of the transistor. In the saturation regime, the mobility was not constant along the channel, and the extracted value only represents a mean value. The mobility was then extracted in linear regime, where the density of charge is uniform. Output characteristics, drain-source current $\mathrm{I}_{\mathrm{DS}}$ as a function of the drain-source voltage $V_{D S}$, were also plotted at different values of the gate-source voltage $V_{G S}$. This representation leads to a better understanding of the OFET behaviour in a circuit. Transfer and output characteristics of $\mathbf{L P P}\left(=\mathbf{C}(\mathbf{C N})_{2}\right)_{2}$ are plotted in Figure $8 \mathrm{a}-\mathrm{b}$. From these transfer characteristics, we note the steep switch from the off to the on state, the low value of the threshold voltage $\left(\mathrm{V}_{\mathrm{TH}}=17 \mathrm{~V}\right.$, the bend of the characteristic at the end of the off-on switch) and the high ratio $\left(2 \times 10^{5}\right)$ between the on and the off currents. The output characteristics (Figure 8b) show very well saturation of the current with low saturation voltage $\mathrm{V}_{\mathrm{DS}}$. It is important to mention that the saturation of the output characteristic at $\mathrm{V}_{\mathrm{GS}}=17 \mathrm{~V}$ starts from low value, less than $10 \mathrm{~V}$, of the drain-source voltage. It means that present OFETs can work at lower voltage than usual ${ }^{38}$ which is a crucial point for CMOS devices. In addition, the $\mathrm{R}_{\mathrm{DSon}} / \mathrm{R}_{\mathrm{DSoff}}$ ratio recorded at ca 100 , calculated from the output characteristics between the saturation and the linear regime, is sufficient to use this n-OFET in CMOS devices. Finally, the subthreshold swing $S$ has been calculated at $1 \mathrm{~V} / \mathrm{dec}$. Thus, the low threshold voltage $\left(\mathrm{V}_{\mathrm{TH}}=17 \mathrm{~V}\right)$ and subthreshold swing $(\mathrm{S}=1 \mathrm{~V} / \mathrm{dec})$ appear to be interesting and promising for future applications. These two parameters are linked (i) to the electrical quality of the insulator-semiconductor interface and (ii) to the proximity of the active layer with the interface. Consequently, the values of $\mathrm{V}_{\mathrm{TH}}$ and $\mathrm{S}$ can be mainly attributed to the better quality of organic - organic interface compared to inorganic-organic one. ${ }^{39} \mathrm{We}$ believe that this finding could be of great interest to obtain in the future full organic devices. The field effect mobility recorded for $\mathbf{L P P}\left(=\mathbf{C}(\mathbf{C N})_{2}\right)_{2}$ is of $1.8 \times 10^{-5} \mathrm{~cm}^{2} / \mathrm{V}$.s. Compared to related compounds with similar design, this value appears to be intermediate between those obtained for dihydro[1,2-b)]fluorene and for bridged tetraphenylenes. Indeed and as mentioned above, Marks, Facchetti and their coworkers have reported, in 2008, the first examples of dihydro[1,2- $b$ )]fluorene and bridged tetraphenylenes incorporating dicyanovinylene units as $\mathrm{n}$ type semi conductors in OFET. ${ }^{5,20}$ Despite, the former does not present any field effect activity, the latter possesses a maximum mobility $\mu_{\mathrm{FE}}$ of 0.006 $\mathrm{cm}^{2} / \mathrm{V}$.s, an $\mathrm{I}_{\mathrm{ON}} / \mathrm{I}_{\mathrm{OFF}}$ of $10^{6}$, and a $\mathrm{V}_{\mathrm{TH}}$ of $30 \mathrm{~V} .{ }^{5}$ Thus, the structurally related pentaphenylene derivative $\mathbf{L P P}\left(=\mathbf{C}(\mathbf{C N})_{2}\right)_{2}$ appears to be more efficient than the dicyanovinylenedihydro[1,2-b)]fluorene (no field effect activity) but less efficient than the dicyanovinylene bridged tetraphenylene. Indeed, compared to the former, $\mathbf{L P P}\left(=\mathbf{C}(\mathbf{C N})_{2}\right)_{2}$ possesses a lower field effect mobility and a lower $\mathrm{I}_{\mathrm{ON}} / \mathrm{I}_{\mathrm{OFF}}$ but presents nevertheless a lower $\mathrm{V}_{\mathrm{TH}}$. In the light of these results, it is clear that the length of the central $\pi$-conjugated system $(3,4$ or 5 phenyl units) and its geometry is a key factor for the field effect activity. 

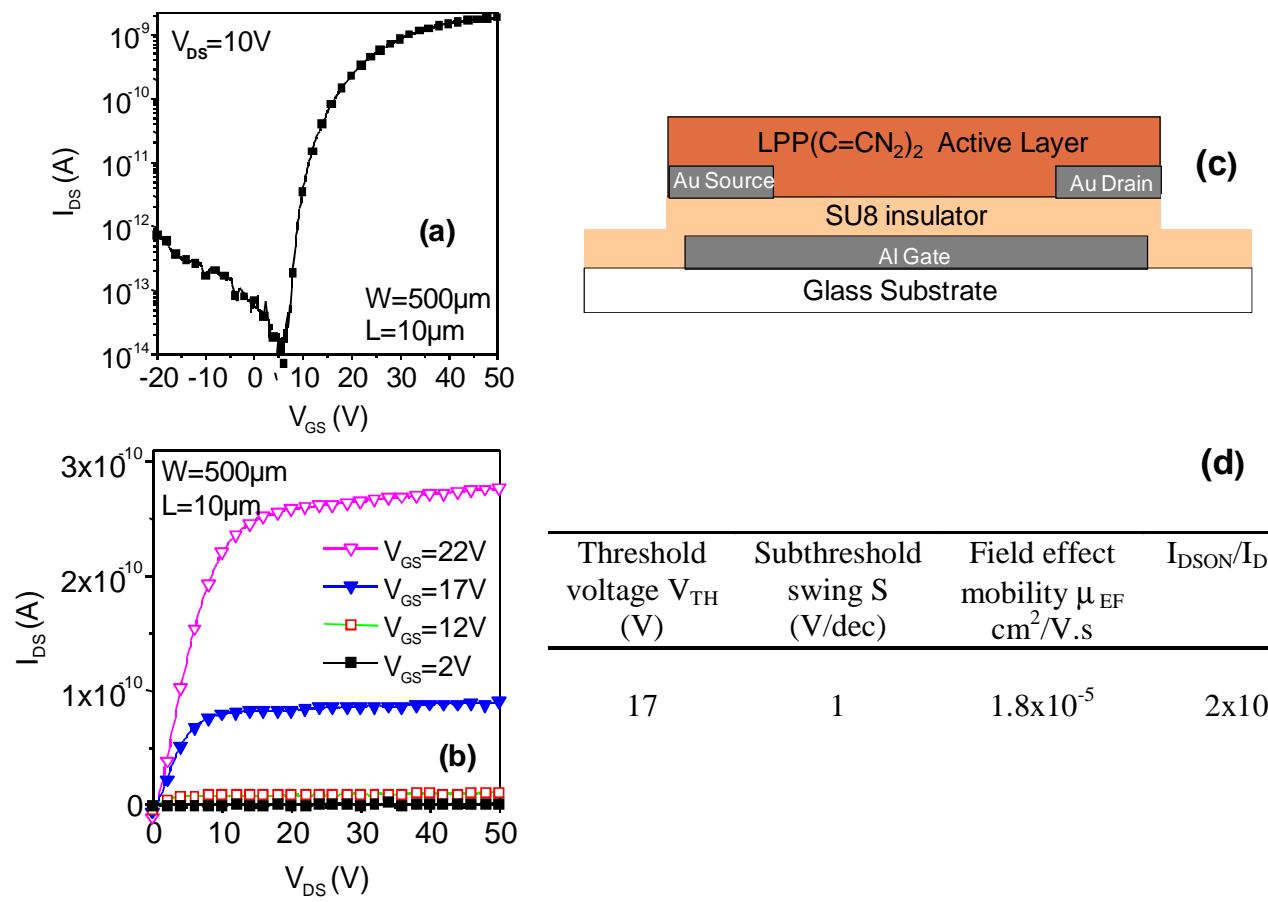

(d)

\begin{tabular}{cccc}
\hline $\begin{array}{c}\text { Threshold } \\
\text { voltage } \mathrm{V}_{\mathrm{TH}} \\
(\mathrm{V})\end{array}$ & $\begin{array}{c}\text { Subthreshold } \\
\text { swing S } \\
(\mathrm{V} / \mathrm{dec})\end{array}$ & $\begin{array}{c}\text { Field effect } \\
\text { mobility } \mu_{\mathrm{EF}} \\
\mathrm{cm}^{2} / \mathrm{V} . \mathrm{s}\end{array}$ & $\mathrm{I}_{\text {DSON }} / \mathrm{I}_{\text {DSOFF }}$ \\
\hline & 1 & $1.8 \times 10^{-5}$ & $2 \times 10^{5}$
\end{tabular}

Figure 8. left: Transfer (a) and output (b) characteristics of an n-OFET with $500 \mu \mathrm{m}$ wide and $10 \mu \mathrm{m}$ long channel. Right: Bottom Gate - Bottom Contacts structure of the present $\mathrm{n}$ channel OFETs (c) and main parameters of the OFET calculated from the characteristics of a) and b).

The stability of the devices under nitrogen atmosphere and under ambient is one of the most important parameter for practical use. We analysed the transfer characteristic and first observed a degradation of the drain current under nitrogen atmosphere. In Figure 9, the variation of the drain current at $\mathrm{V}_{\mathrm{GS}}=30 \mathrm{~V}$ during the whole period of 6 months is shown. The behaviour of this degradation is exponential and most of the degradation takes place in the first 6 days before to be stable for the 6 following months. This first experience is an important indication of the expected stability of the $\mathbf{L P P}\left(=\mathbf{C}(\mathbf{C N})_{2}\right)_{2}$ based OFET.

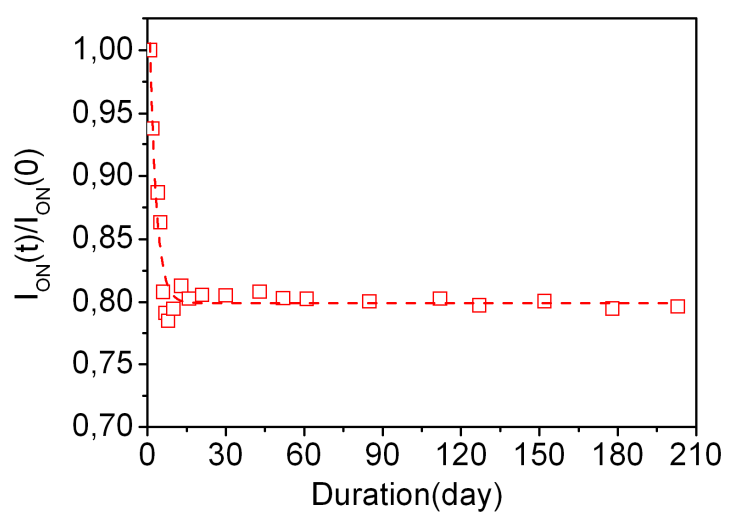

Figure 9. Behaviour under nitrogen atmosphere of the ratio $\mathrm{I}_{\mathrm{ON}}(\mathrm{t}) / \mathrm{I}_{\mathrm{ON}}(0)$ with $\mathrm{I}_{\mathrm{ON}}(\mathrm{t})$ being the on-current at $t$ and $\mathrm{I}_{\mathrm{ON}}(0)$ being the on-current just after the fabrication of the OFET.

More important than the stability under nitrogen is the environmental stability, which is one of the key point nowadays in OFET technology. ${ }^{3}$ Thus, in order to study this stability under harsh ambient conditions, the n-type OFET was released to the air. It is indeed known that the 
instability of organic radical anions (generated by reduction of the active layer at the cathode) in the presence of oxygen and water avoids the OFET to work under ambient conditions. ${ }^{2}$ The behaviour of the normalized drain current is shown in figure 10 as a function of the exposure time to air. Instantly, the current decreases by a factor 3 (Figure 10-inset) but quickly stabilizes ( 5 minutes) and then appears to be stable even after 2 months. The strong decrease of current is frequently observed for $n$-channel OFETs ${ }^{24,40,41}$ and has been tentatively assigned to the physically adsorbed oxygen and/or water, ${ }^{41}$ despite this feature has not been fully unravelled. In our case, after storage under ambient atmosphere for 2 months, the initial current of $\mathbf{L P P}\left(=\mathbf{C}(\mathbf{C N})_{2}\right)_{2}$ based OFET is fully recovered when carrying out the measurements under reduce pressure. This feature seems to be in accordance with the abovementioned conclusions. This ambient stability is undoubtedly related to the very low LUMO level of $\mathbf{L P P}\left(=\mathbf{C}(\mathbf{C N})_{2}\right)_{2}(-4.02 \mathrm{eV})$ which is essential to stabilize the electrons during the charge transport. This conclusion is consistent with the recent chemical design rules, which have clearly highlighted that the LUMO level of the organic semi conductors should be below $-4 \mathrm{eV}$ to obtain air stable OFET. ${ }^{2}$

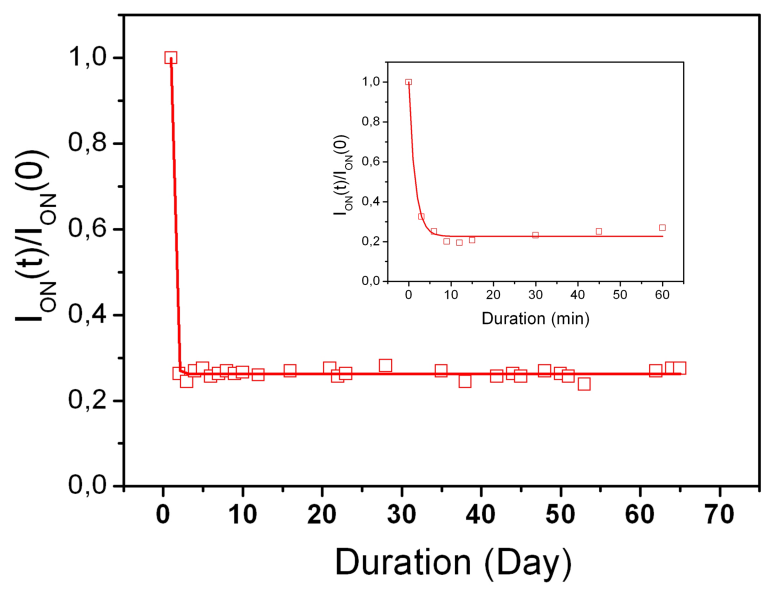

Figure 10. Behaviour of the ratio $\mathrm{I}_{\mathrm{ON}}(\mathrm{t}) / \mathrm{I}_{\mathrm{ON}}(0)$ with $\mathrm{I}_{\mathrm{ON}}(\mathrm{t})$ being the on-current at $\mathrm{t}$ in air and $\mathrm{I}_{\mathrm{ON}}(0)$ being the on-current under nitrogen atmosphere before releasing the OFET outside of the glove box.

As the electrical stability of the organic material is also an important feature in OFET technology, gate bias stress was applied to the device. If $\mathbf{L P P}\left(=\mathbf{C}(\mathbf{C N})_{2}\right)_{2}$ appears to be stable according to the bias effect, only a shift of $\mathrm{V}_{\mathrm{TH}}$ and $\mathrm{I}_{\mathrm{DS}}$ will be detected. In addition, the degradation of the charge carrier mobility is related to a change of the subthreshold swing S. Thus, two important conclusions would be drawn from this measurement (i) the quality of the interface between the organic semi conductor and the insulating layer and (ii) the stability of the active layer. Thus, gate bias stress was applied to the OFET (Figure 8) and the transfer characteristics at $\mathrm{V}_{\mathrm{DS}}=10 \mathrm{~V}$ plotted at different times of the stress. During the stress, $+40 \mathrm{~V}$ gate bias was applied with shortened drain and source contacts. Figure 11 shows the behaviour of the threshold voltage, the on-current and the subthreshold swing during this stress. Remarkably, the subthreshold swing $\mathrm{S}$ appears to be constant during this stress clearly indicating that the electrical quality of the semiconductor-insulator interface is not modified during the stress. No creation of defects occurs at this interface or inside the bottom part of the active layer close to the insulator. To support this conclusion, the on-current as a function of the threshold voltage during the stress was plotted in Figure 11 (b) and the resulting curve 
appears to be perfectly linear. From the equation (1), this linearity means constant slope $\mathrm{W}_{\mu} \mathrm{C}_{\mathrm{INS}} \mathrm{V}_{\mathrm{DS}} / \mathrm{L}$ and then constant field effect mobility $\mu$ during the stress. The electron transport in the OFET channel is hence stable during the stress clearly highlighting the electrical stability of $\mathbf{L P P}\left(=\mathbf{C}(\mathbf{C N})_{2}\right)_{2}$ to the gate bias stress.
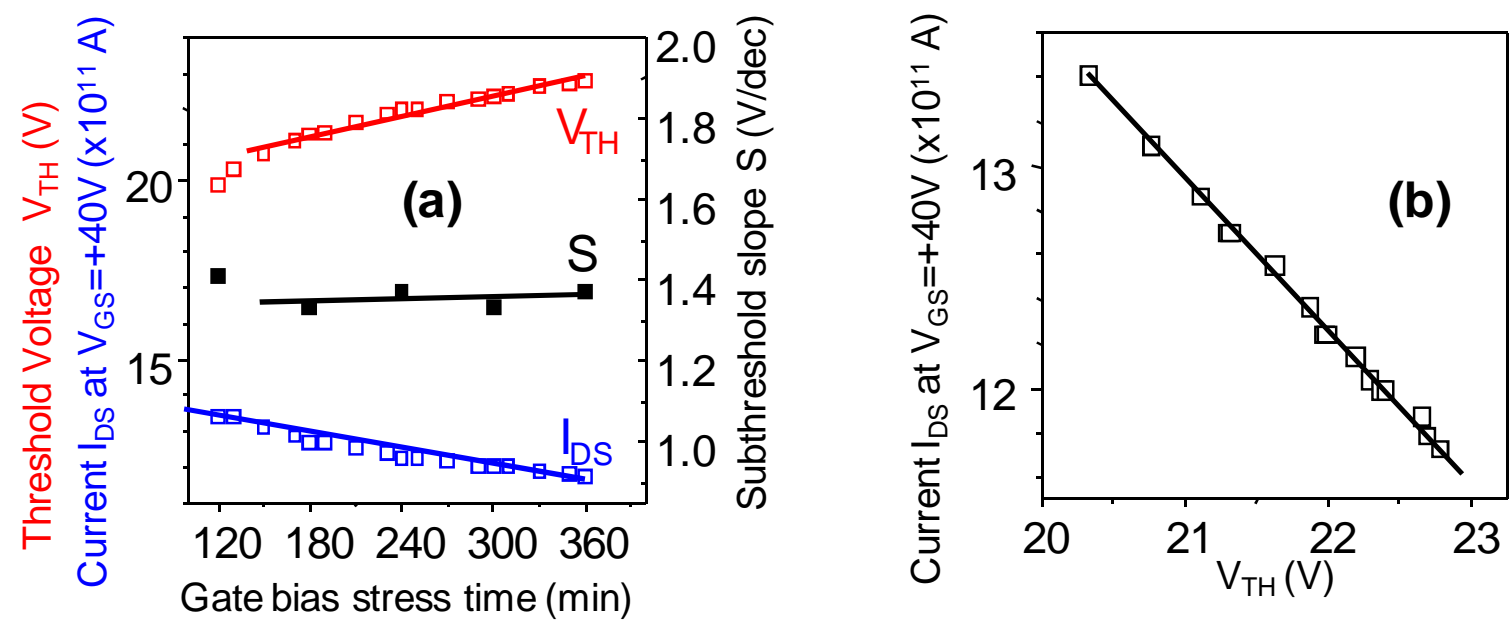

Figure 11. (a) Behaviour of the threshold voltage $V_{T H}$, the on-current $I_{D S}$ at $V_{G S}=+40 \mathrm{~V}$ and the subthreshold swing $\mathrm{S}$ during a gate bias stress $\left(\mathrm{V}_{\mathrm{GS}}=+40 \mathrm{~V}\right.$ and $\left.\mathrm{V}_{\mathrm{DS}}=0\right)$. (b) Perfect linearity between $\mathrm{I}_{\mathrm{DS}}$ and $\mathrm{V}_{\mathrm{TH}}$ during this stress.

In conclusion, a new bridged pentaphenylene derivative functionnalized with dicyanovinylene units $\mathbf{L P P}\left(=\mathbf{C}(\mathbf{C N})_{2}\right)_{2}$ has been synthesized and characterized. The properties have been carefully studied through a combined experimental and theoretical approach and compared to those of two pentaphenylene derivatives bearing methylenes or carbonyl units on the bridgeheads. Such a structure/properties relationship study has notably allowed highlighting the strong electron-withdrawing character of the dicyanovinylene groups, which impressively affect the LUMO energy and in a less extend the HOMO energy. Thus, $\mathbf{L P P}\left(=\mathbf{C}(\mathbf{C N})_{2}\right)_{2}$ possesses a very low LUMO level, ca $-4.02 \mathrm{eV}$, indicating the efficiency of the present chemical design. Finally, $\mathbf{L P P}\left(=\mathbf{C}(\mathbf{C N})_{2}\right)_{2}$ has been successfully used as active layer in n-channel OFETs using organic SU8 as gate insulator. With an electron mobility evaluated at ca $1.8 \times 10^{-5} \mathrm{~cm}^{2} / \mathrm{V}$.s, $\mathbf{L P P}\left(=\mathbf{C}(\mathbf{C N})_{2}\right)_{2}$ based n-channel OFETs showed low voltage functioning (low gate-source and drain-source voltages), interesting subthreshold swing and excellent stability under electrical stress, under nitrogen and more importantly under ambient atmosphere. This work not only represents, to the best of our knowledge, the first report of pentaphenylene-based semiconductor in n-type OFET but highlights the great potential of such type of materials to provide air stable OFET. In the light of these preliminary findings, other bridged oligophenylenes derivatives (notably based on new positional isomers of dihydro[2,1-a)], ${ }^{12,27}[2,1-b],{ }^{6,42}$-fluorene for example) are currently designed in our group for n-channel OFET applications.

\section{Experimental part:}

Synthesis:

THF was distilled from sodium/benzophenone prior to use. Light petroleum refers to the fraction with bp $40-60{ }^{\circ} \mathrm{C}$. Reactions were stirred magnetically, unless otherwise indicated. Analytical thin layer chromatography was carried out using 
aluminium backed plates coated with Merck Kieselgel 60 GF254 and visualized under UV light (at 254 and/or $365 \mathrm{~nm}$ ). Chromatography was carried out using silica 60A CC 40-63 $\mathrm{mm}$ (SDS). ${ }^{1} \mathrm{H}$ and ${ }^{13} \mathrm{C}$ NMR spectra were recorded using Bruker $300 \mathrm{MHz}$ instruments $\left({ }^{1} \mathrm{H}\right.$ frequency, corresponding ${ }^{13} \mathrm{C}$ frequency is $75 \mathrm{MHz}$ ); chemical shifts were recorded in ppm and $\mathrm{J}$ values in $\mathrm{Hz}$. In the ${ }^{13} \mathrm{C}$ NMR spectra, signals corresponding to $\mathrm{CH}, \mathrm{CH}_{2}$ or $\mathrm{Me}$ groups, assigned from DEPT, are noted; all others are C. The residual signals for the NMR solvents are: $\mathrm{CDCl}_{3}: 77.00 \mathrm{ppm}$ for the carbon; $7.26 \mathrm{ppm}$ for the proton; The following abbreviations have been used for the NMR assignment: $\mathrm{s}$ for singlet, $\mathrm{d}$ for doublet, $\mathrm{t}$ for triplet and $\mathrm{m}$ for multiplet. High resolution mass spectra were recorded at the Centre Régional de Mesure Physique de l'Ouest (Rennes). Names have been generated with the name program of the ACD ILab web site. $\mathbf{L P P}(=\mathbf{O})_{2}$ namely 9,9,18,18-tetraoctyl-9,18-dihydrobenzo[5,6]-sindaceno[1,2- $b]$ indeno[2,1- $h]$ fluorene-6,15-dione has been synthesized and purified according to literature procedures with spectroscopic analyses and purity in accordance with our previous work. ${ }^{15}$

2,2'-(9,9,18,18-tetramethyl-9,18-dihydrobenzo[5,6]-s-indaceno[1,2- $b]$ indeno[2,1- $h]$ fluorene6,15-diylidene)dipropanedinitrile $\mathbf{L P P}\left(=\mathbf{C}(\mathbf{C N})_{2}\right)_{2}$

$\mathbf{L P P}(=\mathbf{O})_{2}(100 \mathrm{mg}, 0.11 \mathrm{mmol})$ and malononitrile $(30 \mathrm{mg}, 0.45 \mathrm{mmol})$ were dissolved in dry chlorobenzene $(20 \mathrm{~mL})$ under an argon atmosphere. Pyridine $(0.21 \mathrm{~mL}, 0.0026 \mathrm{mmol})$ and titanium tetrachloride $(0.14 \mathrm{~mL}, 0.0012 \mathrm{mmol})$ were added via syringe. The resulting mixture was refluxed over 4 hours during which the colour of the solution became green. Upon cooling water $(50 \mathrm{~mL})$ was added and the product was extracted with dichloromethane. The organic phase was dried over $\mathrm{MgSO}_{4}$, filtered and dried in vacuo. The crude product was purified by column chromatography on silica gel eluting with dichloromethane/light petroleum (1:4) to give the title compound $\mathbf{L P P}\left(=\mathbf{C}(\mathbf{C N})_{2}\right)_{\mathbf{2}}(100 \mathrm{mg}, 91 \%)$ as a dark green solid. Mp. $225^{\circ} \mathrm{C} ;{ }^{1} \mathrm{H}$ NMR $\left(300 \mathrm{MHz} ; \mathrm{CDCl}_{3}\right) \delta 8.73(\mathrm{~s}, 2 \mathrm{H} ; \mathrm{ArH}), 8.57(\mathrm{~s}, 2 \mathrm{H} ; \mathrm{ArH}), 7.78$ $\left(\mathrm{dd},{ }_{3} \mathrm{~J}=5.4,{ }_{4} \mathrm{~J}=2.4,2 \mathrm{H} ; \mathrm{ArH}\right), 7.52(\mathrm{~s}, 2 \mathrm{H} ; \mathrm{ArH}), 7.41-7.38(\mathrm{~m}, 6 \mathrm{H} ; \operatorname{ArH}), 2.06(\mathrm{t}, J=8.1,8 \mathrm{H}$; $\mathrm{CH}_{2}$ ), 1.26-1.07 (m, 40H; $\left.\mathrm{CH}_{2}\right), 0.80(\mathrm{t}, \mathrm{J}=6,12 \mathrm{H} ; \mathrm{Me}), 0.64-0.62 \mathrm{ppm}\left(\mathrm{m}, 8 \mathrm{H} ; \mathrm{CH}_{2}\right) ;{ }^{13} \mathrm{C}$ NMR (300 MHz; $\left.\mathrm{CDCl}_{3}\right) \delta 160.1(\mathrm{C}), 150.5(\mathrm{C}), 143.5(\mathrm{C}), 143.4(\mathrm{C}), 140.6(\mathrm{C}), 139.8(\mathrm{C})$, $139.1(\mathrm{C}), 133.5(\mathrm{C}), 128.5(\mathrm{CH}), 127.3(\mathrm{CH}), 122.9(\mathrm{CH}), 120.2(\mathrm{CH}), 118.2(\mathrm{CH}), 117.9$ $(\mathrm{CH}), 115.4(\mathrm{CH}), 113.5(\mathrm{C}) 113.3(\mathrm{C}), 76.8(\mathrm{C}=), 56.3(\mathrm{C}), 40.1\left(\mathrm{CH}_{2}\right), 31.7\left(\mathrm{CH}_{2}\right), 29.8$ $\left(\mathrm{CH}_{2}\right), 29.2\left(\mathrm{CH}_{2}\right), 29.1\left(\mathrm{CH}_{2}\right), 23.8\left(\mathrm{CH}_{2}\right), 22.5\left(\mathrm{CH}_{2}\right), 14.0 \mathrm{ppm}(\mathrm{Me}) ; \mathrm{IR}(\mathrm{KBr}) \mathrm{v}=3061$, 3013, 2925, 2852, $2223(\mathrm{CN}), 1606,1465,1436,1421,1143,910 \mathrm{~cm}^{-1}$ HRMS (ESI+, $\mathrm{CH}_{2} \mathrm{Cl}_{2} / \mathrm{MeOH}: 1 / 9$ ): $\mathrm{m} / z$ calcd for $\mathrm{C}_{72} \mathrm{H}_{82} \mathrm{~N}_{4}$ : 1002.65395 [M]+•; found: 1002.6559; elemental analysis calcd (\%) for $\mathrm{C}_{72} \mathrm{H}_{82} \mathrm{~N}_{4}$ : C, 86.18; H, 8.24; N, 5.58; found C,85.77; H,8.19; N, 5.78.

Photophysical studies

Cyclohexane (ACS grade), dichloromethane (analytical grade, VWR) and absolute ethanol was used without further purification. THF was distilled from sodium/benzophenone prior to use. UV/Vis spectra were recorded by using a UV/Vis SHIMADZU UV-1605 spectrophotometer. The optical gap was calculated from the absorption edge of the UV/Vis absorption spectra by using the formula $\Delta$ Eopt $[\mathrm{eV}]=\mathrm{hc} / \lambda, \lambda$ being the absorption edge (in meter). With $\mathrm{h}=6.6 \times 10^{-34} \mathrm{~J} . \mathrm{s}\left(1 \mathrm{eV}=1.6 \times 10^{-19} \mathrm{~J}\right)$ and $\mathrm{C}=3.0 \times 10^{8} \mathrm{~ms}^{-1}$, this equation may be simplified as: $\Delta$ Eopt $[\mathrm{eV}]=1237.5 / \lambda$ (in $\mathrm{nm}$ ). Photoluminescence spectra were recorded with a PTI spectrofluorimeter (PTI-814PDS, MD 5020, LPS 220B) by using a xenon lamp. 


\section{Electrochemical studies}

$\mathbf{L P P}\left(=\mathbf{C}\left(\mathbf{C N}_{2}\right)_{2}\right.$ has been studied using cyclic and differential pulse voltammetry (CV and DPV). All electrochemical experiments were performed under an argon atmosphere, using a Pt disk electrode (Ø: $1 \mathrm{~mm}$ ), the counter electrode was a vitreous carbon rod and the reference electrode was a silver wire in a $0.1 \mathrm{M} \mathrm{AgNO}$ solution in $\mathrm{CH}_{3} \mathrm{CN}$. Ferrocene was added to the electrolytic solution at the end of a series of experiments. The ferrocene/ferrocenium $\left(\mathrm{Fc} / \mathrm{Fc}^{+}\right)$ couple served as the internal standard. All potentials are referred to the SCE electrode that was calibrated at $-0.405 \mathrm{~V} v \mathrm{v}$. $\mathrm{Fc} / \mathrm{Fc}^{+}$system. Activated $\mathrm{Al}_{2} \mathrm{O}_{3}$ was added to the electrolytic solution to remove excess moisture. The three electrode cell was connected to a PAR Model 273 potentiostat/galvanostat (PAR, EG\&G, USA) monitored with the ECHEM Software.

\section{Theoretical modeling:}

Full geometry optimization with Density functional theory (DFT) $)^{43-45}$ and Time-Dependent Density Functional Theory (TD-DFT) calculation were performed with the hybrid Becke-3 parameter exchange ${ }^{46-48}$ functional and the Lee-Yang-Parr non-local correlation functional ${ }^{49}$ (B3LYP) implemented in the Gaussian 09 (Revision B.01) program suite ${ }^{50}$ using the 6$311 \mathrm{G}+(\mathrm{d}, \mathrm{p})$ basis set and the default convergence criterion implemented in the program. The figures were generated with Gauss View 5.0.

Thermal analyses:

Thermogravimetric analyses (TGA) were carried out with a a Rigaku Thermoflex instrument or a SDT Q600 (TA instrument) under a nitrogen atmosphere at a heating rate of $5^{\circ} \mathrm{C} / \mathrm{min}$. Differential scanning calorimetry (DSC) was carried out by using NETZSCH DSC 200 F3 instrument equipped with an intracooler. DSC traces were measured at $10{ }^{\circ} \mathrm{C} / \mathrm{min}$ (2 heating cycles). Melting points were determined with DSC.

\section{OFET Fabrication}

A $100 \mathrm{~nm}$ thick aluminum layer is thermally evaporated on previously cleaned glass substrate. This layer was wet etched to define the gate contact. The insulator (SU-8 photoresist 2000.5 from Microchem) was spin-coated and annealed. The final thickness of this SU-8 layer is about $300 \mathrm{~nm}$. Evaporation of $50 \mathrm{~nm}$ thick gold layer follows. This layer was wet etched to form the source and drain contacts. Gold was chosen due to its stability and its work function, $-5 \mathrm{eV}$, that is compatible with the LUMO level, $-4.02 \mathrm{eV}$, of $\mathbf{L P P}\left(=\mathbf{C}(\mathbf{C N})_{2}\right)_{2}$. The last step is the evaporation under vacuum $\left(10^{-6}-10^{-7} \mathrm{mbar}\right)$ of $20 \mathrm{~nm}$ thick $\mathbf{L P P}\left(=\mathbf{C}(\mathbf{C N})_{2}\right)_{2}$ layer with a deposition rate about $0.2 \mathrm{~nm} / \mathrm{s}$. All the patterning steps have been made with classical photolithography tools.

Quantitatively, the different OFET parameters can be calculated using the known relation (1) between the drain-source current and the drain-source and gate-source voltages in the linear regime.

$$
\mathrm{I}_{\mathrm{DS}}=\frac{\mathrm{W} \mu \mathrm{C}_{\mathrm{INS}}}{\mathrm{L}}\left(\mathrm{V}_{\mathrm{GS}}-\mathrm{V}_{\mathrm{TH}}\right) \mathrm{V}_{\mathrm{DS}}
$$

In this equation, $\mathrm{L}$ is the channel length (in $\mu \mathrm{m}$ ), $\mathrm{W}$ the channel width (in $\mu \mathrm{m}$ ), $\mathrm{C}_{\mathrm{INS}}$ (in $\mathrm{F} / \mathrm{cm}^{2}$ ) is the capacitance of the gate insulator per area unit, and $\mu$ (in $\mathrm{cm}^{2} / \mathrm{V}$.s) is the field effect mobility, $\mathrm{V}_{\mathrm{GS}}$ (in $\mathrm{V}$ ) is the gate source voltage, $\mathrm{V}_{\mathrm{TH}}\left(\mathrm{in} \mathrm{V}\right.$ ) is the threshold voltage and $\mathrm{V}_{\mathrm{DS}}$ (in $\mathrm{V})$ is the drain source voltage. 
The threshold voltage $\mathrm{V}_{\mathrm{TH}}$ can be determined by a linear extrapolation on the gate voltage axis of the transfer characteristic $\mathrm{I}_{\mathrm{DS}}-\mathrm{V}_{\mathrm{GS}}$ at constant $\mathrm{V}_{\mathrm{DS}}$. The field effect mobility can be calculated from the slope $\mathrm{W} \mu \mathrm{C}_{\mathrm{INS}} \mathrm{V}_{\mathrm{DS}} / \mathrm{L}$ of this linear extrapolation.

The switch from the off to the on state is quantified by the subthreshold swing $\mathrm{S}$ that is the inverse of the maximum slope of the transfer characteristics plotted in semi-logarithmic plot.

\section{ACKNOWLEDGMENTS}

We wish to thank the C.R.M.P.O (Rennes) for mass and CHN analysis, the CINES (Montpellier) for computing time, the Region Bretagne and the Agence de l'Environnement et de la Maîtrise de l'Energie (ADEME) for a studentship (MR), Michele Chevrier and Sébastien Thiery (Rennes) for their help in UV-Vis absorption and fluorescence experiments, Dr Nicolas Cocherel (Rennes) for his help in synthesis, Dr Frédéric Barrière (Rennes), Dr Eric Le Fur for TGA measurment and Dr Rémi Métivier for their helps and advices in DFT and TD-DFT calculations. The authors wish also to highly thank the Agence National de la Recherche for financial support (Project ANR HOME-OLED $n^{\circ}$ ANR-11-BS07-020-01).

\section{REFERENCES}

1 C. Wang, H. Dong, W. Hu, Y. Liu, D. Zhu, Chem. Rev. 2012, 112, 2208.

2 H. Usta, A. Facchetti, T. J. Marks, Acc. Chem. Res. 2011, 44, 501.

3 Q. Meng, W. Hu, Phys. Chem. Chem. Phys. 2012, 14, 14152.

4 D. M. de Leeuw, M. M. J. Simenon, A. R. Brown, R. E. F. Einerhand, Synth. Met. 1997, 87, 53.

5 H. Usta, C. Risko, Z. Wang, H. Huang, M. K. Deliomeroglu, A. Zhukhovitskiy, A. Facchetti, T. J. Marks, J. Am. Chem. Soc. 2009, 131, 5586.

6 M. Romain, D. Tondelier, J.-C. Vanel, B. Geffroy, O. Jeannin, J. Rault-Berthelot, R. Métivier, C. Poriel, Angew. Chem. Int. Ed. 2013, in press 10.1002/anie.201306668.

7 D. Thirion, M. Romain, J. Rault-Berthelot, C. Poriel, J. Mater. Chem. 2012, 22, 7149.

8 D. Thirion, J. Rault-Berthelot, L. Vignau, C. Poriel, Org. Lett. 2011, 13, 4418.

9 C. Poriel, J.-J. Liang, J. Rault-Berthelot, F. Barrière, N. Cocherel, A. M. Z. Slawin, D. Horhant, M. Virboul, G. Alcaraz, N. Audebrand, L. Vignau, N. Huby, G. Wantz, L. Hirsch, Chem. Eur. J. 2007, 13, 10055.

10 N. Cocherel, C. Poriel, L. Vignau, J.-F. Bergamini, J. Rault-Berthelot, Org. Lett. 2010, 12, 452.

11 C. Poriel, J. Rault-Berthelot, D. Thirion, J. Org. Chem. 2013, 73, 886.

12 D. Thirion, C. Poriel, J. Rault-Berthelot, F. Barrière, O. Jeannin, Chem. Eur. J. 2010, 16, 13646.

13 Y. Park, J.-H. Lee, D. H. Jung, S.-H. Liu, Y.-H. Lin, L.-Y. Chen, C.-C. Wu, J. Park, J. Mater. Chem. 2010, 20, 5930.

14 J. Jacob, J. Zhang, A. C. Grimsdale, K. Müllen, M. Gaal, E. J. W. List, Macromolecules 2003, 36, 8240.

15 N. Cocherel, C. Poriel, J. Rault-Berthelot, F. Barrière, N. Audebrand, A. M. Z. Slawin, L. Vignau, Chem. Eur. J. 2008, 14, 11328.

16 N. Cocherel, C. Poriel, O. Jeannin, A. Yassin, J. Rault-Berthelot, Dyes Pigm. 2009, 83, 339.

17 C. Poriel, N. Cocherel, J. Rault-Berthelot, L. Vignau, O. Jeannin, Chem. Eur. J. 2011, 17, 12631. 
C. E. Finlayson, J.-S. Kim, M. Liddell, R. H. Friend, S.-H. Jung, A. C. Grimsdale, K. Müllen, J. Chem. Phys. 2008, 128, 044703.

J. Jacob, S. Sax, T. Piok, E. J. W. List, A. C. Grimsdale, K. Müllen, J. Am. Chem. Soc. 2004, 126, 6987.

20 H. Usta, A. Facchetti, T. J. Marks, Org. Lett. 2008, 10, 1385.

21 T. Nakagawa, D. Kumaki, J.-I. Nishida, S. Tokito, Y. Yamashita, Chem. Mater. 2008, 20, 2615.

22 S. Chaurasia, Y.-C. Chen, H.-H. Chou, Y. S. Wen, J. T. Lin, Tetrahedron 2012, 68, 7755.

23 H. Usta, A. Facchetti, T. J. Marks, J. Am. Chem. Soc. 2008, 130, 8580.

24 Y.-I. Park, J. S. Lee, B. J. Kim, B. Kim, J. Lee, D. H. Kim, S.-Y. Oh, J. H. Cho, J.-W. Park, Chem. Mater. 2011, 23, 4038.

25 J.-I. Nishida, H. Deno, S. Ichimura, T. Nakagawa, Y. Yamashita, J. Mater. Chem. 2012, 22, 4483.

26 H. Koyama, T. Kamikawa, J. Chem. Soc., Perkin Trans. 1 1998, 203.

27 D. Thirion, C. Poriel, R. Métivier, J. Rault-Berthelot, F. Barrière, O. Jeannin, Chem. Eur. J. 2011, 17, 10272.

28 C. B. Nielsen, E. Voroshazi, S. Holliday, K. Cnops, B. P. Rand, I. Mc Culloch J. Mater. Chem. A 2013, 1, 73.

29 A. P. Kulkarni, C. J. Tonzola, A. Babel, S. A. Jenekhe, Chem. Mater. 2004, 16, 4556.

30 C. M. Cardona, W. Li, A. E. Kaifer, D. Stockdale, G. C. Bazan, Adv. Mater. 2011, 23, 2367.

31 M. Zhang, C. Yang, A. K. Mishra, W. Pisula, G. Zhou, B. Schmaltz, M. Baumgarten, K. Müllen, Chem. Commun. 2007, 1704.

L. Oldridge, M. Kastler, K. Müllen, Chem. Commun. 2006, 885.

33 M. Kosaki, Y. Yonezawa, K. Okada, Org. Lett. 2002, 4, 4535.

34 M. Karelson, M. Zerner, J. Am. Chem. Soc. 1990, 112, 9405.

35 A. C. Grimsdale, Current Organic Chemistry 2010, 14, 2196.

36 K. L. Chan, M. Sims, S. I. Pascu, M. Ariu, A. B. Holmes, D. D. C. Bradley, Adv. Funct. Mater. 2009, 19, 2147.

37 C. Poriel, J. Rault-Berthelot, D. Thirion, F. Barrière, L. Vignau, Chem. Eur. J. 2011, 50, 14031.

38 J. E. Anthony, A. Facchetti, M. Heeney, S. R. Marder, X. Zhan, Adv. Mater. 2010, 22, 3876.

39 J. Veres, S. Ogier, G. Lloyd, Chem. Mater. 2004, 16, 4543.

40 T. Anthopoulos, F. B. Kooistra, H. J. Wondergen, D. Kronholm, J. C. Hummelen, D. M. de Leeuw, Adv. Mater. 2006, 18, 1679.

41 Y. Ie, M. Nitani, M. Karakawa, H. Tada, Y. Aso, Adv. Funct. Mat. 2010, 20, 907.

42 C. Poriel, R. Métivier, J. Rault-Berthelot, D. Thirion, F. Barrière, O. Jeannin, Chem. Commun. 2011, 47, 11703.

43 P. Hohenberg, W. Kohn, Phys. Rev. 1964, 136, B864.

44 R. G. Parr, W. Yang, Density-Functional Theory of Atoms and Molecules, Oxford University Press: Oxford, 1989.

45 J.-L. Calais, Int. J. Quantum Chem. 1993, 47, 101.

46 A. D. Becke, Phys. Rev. 1988, 38, 3098.

47 A. D. Becke, J. Chem. Phys. 1993, 98, 5648.

48 A. D. Becke, J. Chem. Phys. 1993, 98, 1372.

49 C. Lee, W. Yang, R. G. Parr, Phys. Rev. B 1988, 37, 785.

50 M. J. Frisch, G. W. Trucks, H. B. Schlegel, G. E. Scuseria, M. A. Robb, J. R.

Cheeseman, R. Scalmani, G. Barone, B. Mennucci, G. A. Petersson, H. Nakatsuji, M. 
Caricato, X. Li, H. P. Hratchian, A. F. Izmaylov, J. Bloino, G. Zheng, J. L.

Sonnenberg, M. Hada, M. Ehara, K. Toyota, R. Fukuda, J. Hasegawa, M. Ishida, T.

Nakajima, Y. Honda, O. Kitao, H. Nakai, T. Vreven, J. A. J. Montgomery, J. E.

Peralta, F. Ogliaro, M. Bearpark, J. J. Heyd, E. Brother, K. N. Kudin, V. N.

Staroverov, R. Kobayashi, J. Normand, K. Raghavachari, A. Rendell, J. C. Burant, S.

S. Iyengar, J. Tomasi, M. Cossi, N. Rega, N. J. Millam, M. Klene, J. E. Knox, C.

Pomelli, J. W. Ochterski, R. L. Martin, K. Morokuma, V. G. Zakrzewski, G. A. Voth, P. Salvador, J. J. Dannenberg, S. Dapprich, A. D. Daniels, O. Farkas, J. B. Foresman, J. V. Ortiz, J. Cioslowski, D. J. Fox, Gaussian 09, version A02, Gaussian, Inc., Wallingford, CT, 2009. 2009. 
GRAPHICAL ABSTRACT

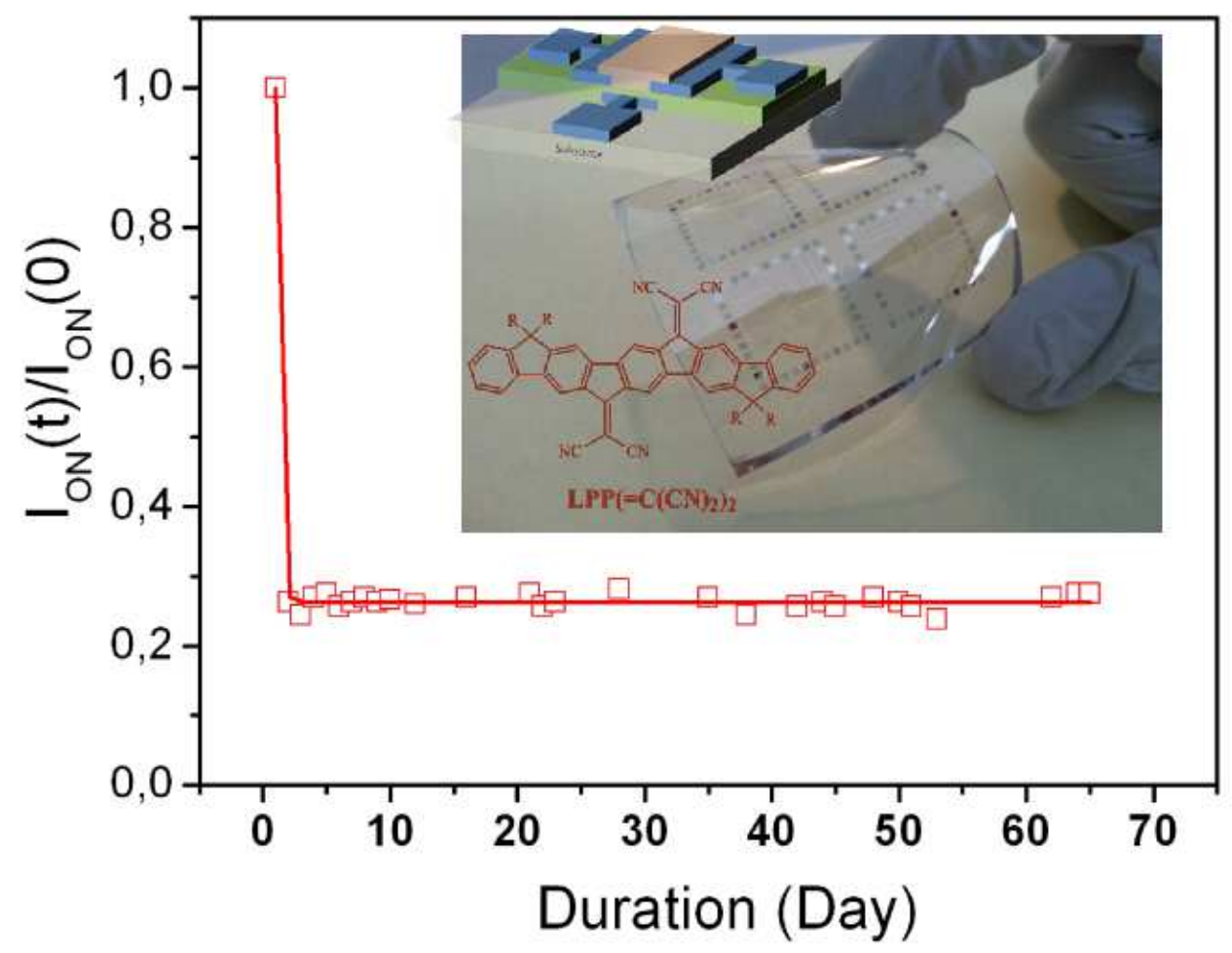

